\title{
Relationship of Three-Dimensional Tomographic Pelvimetry with the Type of Delivery in Patients from Different Nations
}

(1) Engin YILDIRIMa, (1) Vahdet ÖZKOCAK ${ }^{\mathrm{b}}$

aDepartment of Obstetrics and Gynecology, Hitit University Faculty of Medicine,

bepartment of Anthropology, Hitit University

Faculty of Science and Letters, Çorum, TURKEY

Received: 16.08.2018

Received in revised form: 14.10 .2018

Accepted: 22.10.2018

Available online: 15.01 .2019

\section{Correspondence:}

Engin YILDIRIM

Hitit University Faculty of Medicine,

Department of Obstetrics and Gynecology, Corum, TURKEY

enginyildirim@ @itit.edu.tr

\begin{abstract}
Objective: Pelvimetry is defined as the measurement of the female pelvis that helps decide the type of delivery-vaginal or cesarean. Thus, the decision to opt for a cesarean section by the physician depends on the maternal pelvic structure. The present study identified, using three-dimensional (3D) pelvis tomography, whether any relationship existed between the type of delivery and pelvic structure in mothers who had cesarean delivery and vaginal delivery. Material and Methods: The study included participants who underwent 3D tomography for any reason. The first group of patients consisted of mothers who had a vaginal delivery $(\mathrm{n}=89)$, and the second group had a cesarean section after labor started $(n=19)$. Pelvimetry was performed retrospectively on a 3D workstation by a researcher who was blind to the clinical data. The measurements were performed in the diameter between ischial spines (ISD), extending from the top sacral promontory to the superior border of the pubic symphysis (conjugata anatomica [CA]), diameter from the top symphysis pubis in pelvic direction to the top promontory (conjugate obstetrica [CO]), and lower border of symphysis pubis and promontory (conjugate diagonalis [CD]). Tomography resulted in an elliptical shape that was formed by the interspinal diameter extending into the sacrum (approximately S3 vertebra) and was tangent to the top symphysis pubis in the direction of the pelvis (area X). Results: No statistically significant differences were found between the CD, CO, CA, and area $\times$ values of the Turkish and foreign participants ( $\mathrm{p}=0.858,0.867,0.451$, and 0.374 , respectively). The median of the Turkish participants' ISD measurements was found to be higher. No significant differences were found between the participants who had a vaginal delivery and cesarean section in terms of CD, CO, CA, ISD, and area $\times$ values $(\mathrm{p}=0.093,0.984,0.124,0.243,0.796$, respectively). Conclusion: The present study did not find a direct relationship between pelvic measurements and type of delivery.
\end{abstract}

Keywords: Pelvimetry; 3D tomography; cesarean section

he rate of cesarean delivery has seen a recent surge in our country and worldwide, leading to an increase in the maternal and neonatal morbidity and mortality rates. ${ }^{1,2}$ No methods to identify prolonged delivery, predict delivery complications, and foresee the need for the cesarean section have so far been found. Such a method would help in decreasing maternal and neonatal mortality and morbidity.

Various models have been identified for predicting delivery types and outcomes. These include BISHOP scores and various antepartum and intrapartum examination methods. However, these kinds of models generally have limited capacity to predict the delivery outcomes. ${ }^{3,4}$ Sometimes, these methods could be complicated, and they might not be practical during clinical implementations. ${ }^{5,6} \mathrm{~A}$ Cochrane database assessment found that women undergoing pelvimetry were more likely to have a cesarean section. Also, pelvimetry was observed to increase the cesarean rates. ${ }^{7}$ 
The cesarean section could be attributed to the inconsistency between fetal biometry and maternal pelvic structure and insufficient size of maternal pelvis. With high sensitivity and specificity, fetal pelvis index (FPI) described in various studies can predict the ratio of the inconsistency between a fetus and maternal pelvis, but currently, its use is limited. ${ }^{8}$ This method utilizes biometric measurements of the fetus identified by ultrasound in term and the pelvimetry by X-ray. The purpose of the current study was to identify, using 3D pelvis tomography, the relation between the type of delivery and pelvic measurements in mothers who had cesarean delivery and vaginal delivery.

\section{MATERIAL AND METHODS}

The volunteer participants were selected from 870 women who applied to the Hitit University Faculty of Medicine, Erol Olçok Training and Research Hospital between January and August 2018. These women had undergone 3D pelvis tomography due to various medical indications. Computed tomography was performed using a device that enabled 128 slices and remote access (GE Healthcare, Milwaukee, United States). Patients' tomographic images were obtained from the hospital's automation system. The first group of patients consisted of mothers who had a vaginal delivery $(n=89)$ and the second group was formed with mothers who had a cesarean section after labor began $(n=19)$. The exclusion criteria for cesarean section included having no deliveries before, having the first cesarean section before labor started, having cesarean due to fetal distress and malpresentation of diagnosis, having the maternal neck of less than $1.5 \mathrm{~cm}$, having body mass index (BMI) of over 30, and diagnosed with osteoporosis. The exclusion criteria for vaginal delivery included receiving labor induction, not accessing the start and finish partographs of the labor, receiving medications during labor that affected muscle and skeleton systems, and having epidural delivery. When the exclusion and inclusion criteria were applied, 108 patients were included in the study. Before the study was conducted, approval was received from the Ethics Committee of the Hitit University Faculty of Medicine in line with the Declarations of Helsinki. The informed consent form was obtained from the participants who were involved in the study.

The participants' demographic features, nationalities, number of deliveries, delivery types, pregnancy loss, chronic diseases, and medications they had undertaken were recorded in the questionnaire forms through face to face anamnesis. Help from translators was sought while taking anamnesis from foreign patients.

Images obtained from the hospital automation system were restructured into 5 -mm slice thick images. Pelvimetry was performed retrospectively on a 3D workstation (3D Slicer, Version 4.8.1, 2017) by a researcher (I.S.) who was blind to the clinical data using multiplanar images or images processed with volume appropriately. Kappa coefficient, which evaluates the differences between the observer's measurements, was found to be between 0.74 and 0.86 .

While the measurements were performed, they were divided into four different image slices that included pelvic inlet plane, pelvic outlet plane, mid-pelvic plane, and the greatest plane of pelvic diameter. ${ }^{9}$ There are anterior-posterior, two oblique, and one transverse diameter for the pelvic inlet. The present study measured the diameter called "true conjugate" that extends from the top sacral promontory to the superior border of the pubic symphysis (CA). We also measured the diameter from the top symphysis pubis in a pelvic direction to the top promontory (CO). The last measurement was performed between the lower border of symphysis pubis and promontory, which can also be detected by physical examination (CD).

The measurements of pelvis inlet were followed by mid-pelvis measurements. The measurement was performed in the diameter between ISD, the narrowest point of mid-pelvis. An elliptical shape, formed by the interspinal diameter, that extended into the sacrum (approximately S3 vertebra) and was tangent to the top symphysis pubis in the direction of the pelvis, was obtained (area X). The area of the shape was measured and recorded (Figure 1). 
The statistical analysis of the data obtained in this study was performed using SPSS (version 22.0, SPSS Inc., Chicago, IL, United States). Descriptive statistics were presented using mean \pm standard deviation and median (min-max) for continuous variables and numbers and percentages for categorical variables. Normality distribution was performed using Shapiro-Wilk, and Kolmogorov-Smirnov tests. As the mean comparisons of the parameters obtained from the Turkish and foreign participants did not meet the parametric test assumptions, non-parametric Mann-Whitney $\mathrm{U}$ test was applied. A $p$-value of $<0.05$ was considered statistically significant.

\section{RESULTS}

Of the volunteers who participated in the present study, 83 (76.9\%) were Turkish and 25 (23.1\%) were foreign immigrants. There were no significant differences between the average age of the Turkish and foreign participants $(p=0.531$ ). The average age of the Turkish participants was $27.23 \pm 4.525$ years and that of the foreigners was $27.88 \pm 4.604$ years.

An analysis of the type of delivery according to the participants' nationality indicated similar birth rate distributions $(p=1.000)$. Of all the Turkish participants, $81.8 \%$ had a vaginal delivery and $18.1 \%$ had undergone a cesarean section. Among the foreigners, $84 \%$ had a vaginal delivery and $16 \%$ had a cesarean section (Table 1).

No statistically significant differences were found in the CD, CO, CA, and area $\times$ values between the Turkish and foreign participants $(p=$ $0.858,0.867,0.451$, and 0.374 , respectively). However, the ISD values demonstrated statistically significant differences $(p=0.006)$. The median of Turkish participants' ISD measurements was found to be higher (Table 2, Figure 2).

No significant differences were observed between the participants who had a vaginal delivery and cesarean section in terms of CD, CO, CA, ISD, and area $\times$ values $(p=0.093,0.984,0.124,0.243$, and 0.796 , respectively; Table 3 ).

\section{DISCUSSION}

The present study performed pelvimetry on women volunteers to study the relationship be-

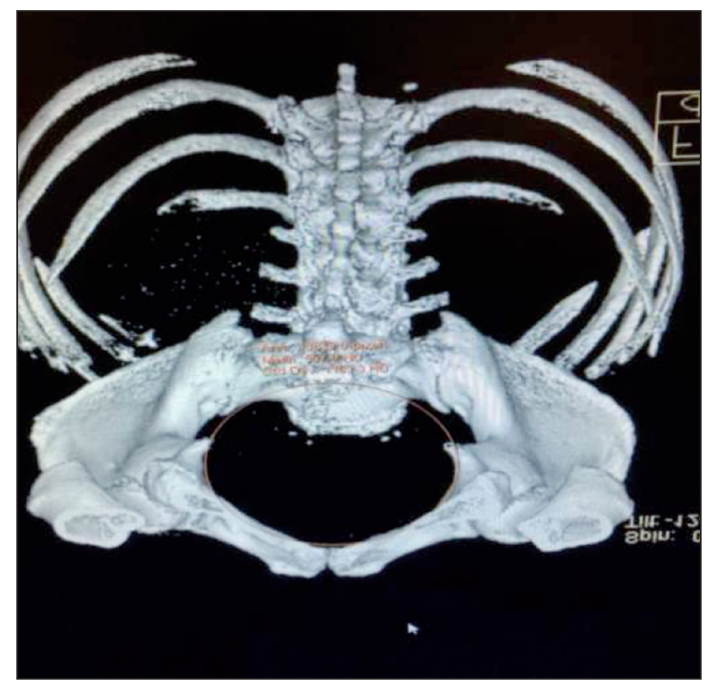

FIGURE 1: Area X measurement.

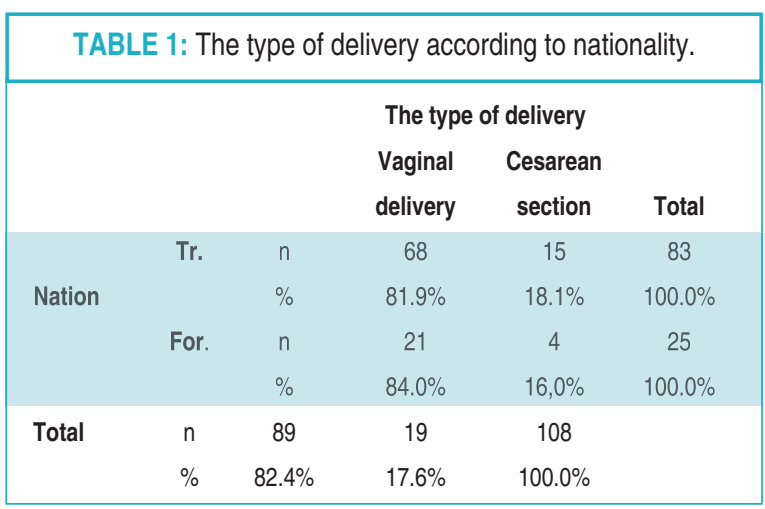

Tr: Turkish citizens; For: Foreigner.

tween maternal pelvic structural and type of delivery. It was observed that the type of delivery was independent of CA, CD, CA, and ISD. Further, the area we identified had no effects on the type of delivery. On analyzing the effect of nationality on anatomic differences, Turkish citizens were found to have a greater interspinous distance. Patients' nationality was found to have no effects on any other anatomic measurements.

When compared to vaginal delivery, cesarean section suffers from various acute and chronic risks. Unplanned cesarean delivery increases patients' morbidity and mortality, and its long-term results are related to subfertility. ${ }^{10,11}$ A study that compared elective cesarean delivery and cesarean delivery that was performed after labor began found emergency cesareans to have higher risks. ${ }^{12}$ The 


\begin{tabular}{|c|c|c|c|c|c|}
\hline & Nation & $\mathrm{n}$ & Mean \pm Std. Deviation & Median (Min-Max) & $P$ value \\
\hline \multirow[t]{2}{*}{$\mathrm{CD}(\mathrm{cm})$} & Tr. & 83 & $13.16 \pm 0.58$ & $13.17(12.01-14.51)$ & 0.858 \\
\hline & For. & 25 & $13.14 \pm 0.61$ & $13.15(12.14-14.25)$ & \\
\hline \multirow[t]{2}{*}{$\mathrm{CO}(\mathrm{cm})$} & Tr. & 83 & $11.13 \pm 0.418$ & $11.21(10.12-12.21)$ & 0.867 \\
\hline & For. & 25 & $11.08 \pm 0.47$ & $11.21(10.21-11.81)$ & \\
\hline \multirow[t]{2}{*}{$\mathrm{CA}(\mathrm{cm})$} & Tr. & 83 & $11.65 \pm 0.44$ & $11.55(11.05-13.51)$ & 0.451 \\
\hline & For. & 25 & $11.70 \pm 0.48$ & $11.65(11.05-13.54)$ & \\
\hline \multirow[t]{2}{*}{ ISD (cm) } & Tr. & 83 & $10.73 \pm 0.47$ & $10.67(9.54-11.98)$ & $0.006^{*}$ \\
\hline & For. & 25 & $10.49 \pm 0.37$ & $10.36(9.96-11.32)$ & \\
\hline \multirow[t]{2}{*}{ Area $\times\left(\mathrm{cm}^{2}\right)$} & Tr. & 83 & $111.10 \pm 5.41$ & $111.250(101.25-118.66)$ & 0.374 \\
\hline & For. & 25 & $109.87 \pm 5.47$ & $108.640(98.69-118.36)$ & \\
\hline
\end{tabular}

* Statistically significant $(p<0.01)$; Mann Whitney U test

CD: Conjugata Diagonalis; CO: Conjugata Obstetrica; CA: Conjugata Anatomica; ISD: Diameter Between Ischial Spines; Tr: Turkish citizens; For: Foreigner.

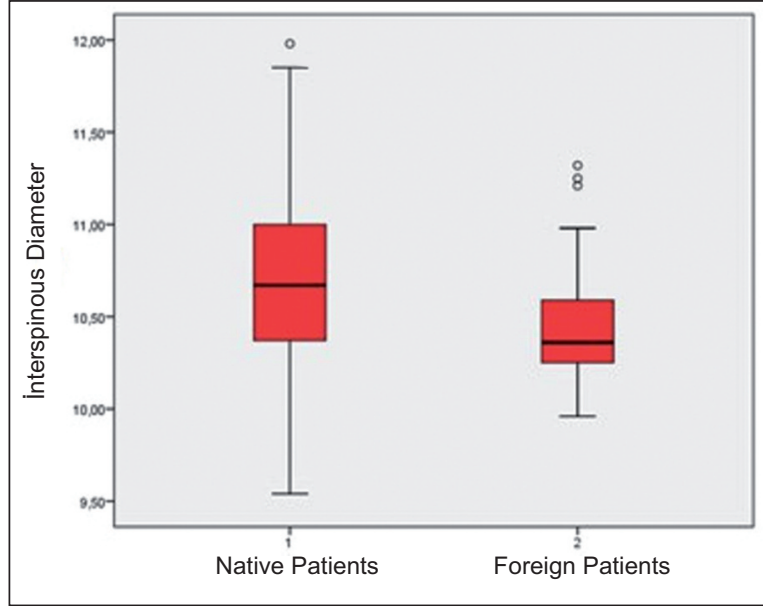

FIGURE 2: Box-Plot graph of interspinous diameter according to nationality. present retrospective study selected participants who had emergency cesarean after active labor had started. This way, we tried to predict pelvimetry due to dystocia that develops during vaginal delivery. Pelvimetric measurements, which have been used for years but have seen a gradual decrease in their use by modern obstetrics, are considered insufficient in predicting the type of delivery without fetal biometric measurements.

Pelvimetry, used in this study, could be compared with studies that investigated interspinous and intertuberous distances, evaluated pelvic outlet in the sagittal plane and performed coccygeal

\begin{tabular}{|c|c|c|c|c|c|}
\hline & Nation & $\mathrm{n}$ & Mean \pm Std. Deviation & Median (Min-Max) & $P$ value \\
\hline \multirow[t]{2}{*}{$\mathrm{CD}(\mathrm{cm})$} & V.B. & 89 & $13.11 \pm 0,59$ & $12,92(12.01-14.51)$ & $0.093^{a}$ \\
\hline & $\mathrm{C} / \mathrm{S}$ & 19 & $13.36 \pm 0.52$ & $13.65(12.47-14.25)$ & \\
\hline \multirow[t]{2}{*}{$\mathrm{CO}(\mathrm{cm})$} & V.B. & 89 & $11.12 \pm 0.43$ & $11.21(10.12-12.21)$ & $0.984^{a}$ \\
\hline & $\mathrm{C} / \mathrm{S}$ & 19 & $11.13 \pm 0.39$ & $11.21(10.25-11.81)$ & \\
\hline \multirow[t]{2}{*}{$\mathrm{CA}(\mathrm{cm})$} & V.B. & 89 & $11.63 \pm 0.42$ & $11.55(11.05-13.51)$ & $0.124^{a}$ \\
\hline & $\mathrm{C} / \mathrm{S}$ & 19 & $11.82 \pm 0.55$ & $11.65(11.13-13.54)$ & \\
\hline \multirow[t]{2}{*}{ ISD (cm) } & V.B. & 89 & $10.70 \pm 0.46$ & $10.65(9.54-11.98)$ & $0.243^{a}$ \\
\hline & $\mathrm{C} / \mathrm{S}$ & 19 & $10.55 \pm 0.41$ & $10.55(9.69-11.34)$ & \\
\hline \multirow[t]{2}{*}{ Area $\times(\mathrm{cm} 2)$} & V.B. & 89 & $110.70 \pm 5.52$ & $110.33(98.69-118.66)$ & $0.796^{a}$ \\
\hline & $\mathrm{C} / \mathrm{S}$ & 19 & $111.35 \pm 5.03$ & $112.51(101.69-116.98)$ & \\
\hline
\end{tabular}

aMann-Whitney U test,

CD: Conjugata Diagonalis; CO: Conjugata Obstetrica; CA: Conjugata Anatomica; ISD: Diameter Between Ischial Spines; N: Number of patients; V.B: Vaginal Birth; C/S: Cesarean Section. 
curve analysis. ${ }^{13,14}$ The present study differs from other studies in terms of "AREA" used that represents the transition from mid-pelvis to the pelvic outlet. However, this area was found to be similar between mothers who had a normal delivery and who had a cesarean section. Previous literature showed variations in dimensions and aspects of fetal pelvis; the aspect, length, and area should not be expected to be the determinants. ${ }^{15}$ Previous studies investigated pelvic measurements of women from different races and, parallel to the present study, these studies found that intrapelvic areas do not indicate any differences that would change the type of delivery. ${ }^{16} \mathrm{~A}$ study involving 426 patients, who had undergone pelvic measurements, showed that the distance formed by the $9-\mathrm{cm}$ diameter that extended into symphysis pubis from S3 vertebra enabled vaginal delivery. The same study reported that the midsagittal mid-pelvis area had no effects on predicting delivery. ${ }^{17}$

Pelvimetric assessment can be used to predict the type of delivery. It can also be used to detect the damage to the pelvic tissue after vaginal delivery. It is possible to detect damage to the levator ani muscle by magnetic resonance (MR) pelvimetry. ${ }^{18}$ Moreover, MR pelvimetry has been shown to be beneficial in suspected fetopelvic disproportion or breech presentation at term. ${ }^{19,20}$

One of the limitations of this study is that the measurements were performed after the birth. This prevented from detecting pelvic changes due to the relaxing hormone secreted during pregnancy and identifying the effect of the pelvis on delivery. An- other limitation of the present study is that no biometric measurements of the fetuses could be performed. The assessment included only pelvis aspects of fetus and pelvis consistency required for delivery.

\section{CONCLUSION}

The present study found no direct relationship between the pelvic measurements and the type of delivery. Also, there was no significant difference in pelvic measurements according to the patient's nationality.

\section{Source of Finance}

During this study, no financial or spiritual support was received neither from any pharmaceutical company that has a direct connection with the research subject, nor from a company that provides or produces medical instruments and materials which may negatively affect the evaluation process of this study.

\section{Conflict of Interest}

No conflicts of interest between the authors and / or family members of the scientific and medical committee members or members of the potential conflicts of interest, counseling, expertise, working conditions, share holding and similar situations in any firm.

\section{Authorship Contributions}

Idea/Concept: Engin Yıldırım; Design: Engin Yıldırım, Vahdet Özkoçak; Control/Supervision: Engin Yıldırım, Vahdet Özkoçak; Data Collection and/or Processing: Engin Yıldırım, Vahdet Özkoçak; Analysis and/or Interpretation: Engin Yıldırım, Vahdet Özkoçak; Literature Review: Engin Yıldırım; Writing the Article: Engin Yıldırım; Critical Review: Engin Yıldırım; References and Fundings: Engin Ylldırım, Vahdet Özkoçak; Materials: Engin Yıldırım. 
1. Lilford RJ, van Coeverden de Groot HA, Moore PJ, Bingham $P$. The relative risks of caesarean section (intrapartum and elective) and vaginal delivery: a detailed analysis to exclude the effects of medical disorders and other acute pre-existing physiological disturbances. Br J Obstet Gynaecol 1990;97(10): 883-92.

2. Ye J, Zhang J, Mikolajczyk R, Torloni MR, Gülmezoglu AM, Betran AP. Association between caesarean section and maternal and neonatal mortality: a worldwide populationbased ecologic study. BJOG 2016;123(5):74553.

3. Wilkes PT, Wolf DM, Kronbach DW, Kunze M, Gibbs RS. Risk factors for cesarean delivery at presentation of nulliparous patients in labor. Obstet Gynecol 2003;102(6):1352-7.

4. Al Housseini A, Newman T, Cox A, Devoe LD. Prediction of risk for cesarean delivery in term nulliparas: a comparison of neural network and multiple logistic regression models. Am J Obstet Gynecol 2009;201(1):113.e1-6.

5. Harlow BL, Frigoletto FD, Cramer DW, Evans $\mathrm{JK}$, Bain RP, Ewigman B, et al. Epidemiologic predictors of cesarean section in nulliparous patients at low risk. RADIUS Study Group: Routine Antenatal Diagnostic Imaging with UItrasound Study. Am J Obstet Gynecol 1995; 172(1 Pt 1):156-62.

6. Turcot L, Marcoux S, Fraser WD. Multivariate analysis of risk factors for operative delivery in nulliparous women. Canadian Early Am-

\section{REFERENCES}

niotomy Study Group. Am J Obstet Gynecol 1997;176(2):395-402.

7. Pattinson RC. Pelvimetry for fetal cephalic presentations at term. Cochrane Database Syst Rev 2000;(2):CD000161.

8. Morgan MA, Thurnau GR, Fishburne JI Jr. The fetal-pelvic index as an indicator of fetalpelvic disproportion: a preliminary report. Am J Obstet Gynecol 1986;155(3):608-13.

9. Cunningham FG, Leveno KJ, Bloom SL, et al. Chapter 2. Maternal anatomy. Williams Obstetrics. $23^{\text {th }}$ ed. New York: McGraw-Hill; 2010. p.14-35.

10. Sachs BP, McCarthy BJ, Rubin G, Burton A, Terry J, Tyler CW Jr. Cesarean section: risk and benefits for mother and fetus. JAMA 1983;250(16):2157-9.

11. Keag $\mathrm{OE}$, Norman JE, Stock SJ. Long-term risks and benefits associated with cesarean delivery for mother, baby, and subsequent pregnancies: Systematic review and metaanalysis. PLoS Med 2018;15(1):e1002494.

12. McMahon MJ, Luther ER, Bowes WA Jr, OIshan AF. Comparison of a trial of labor with an elective second cesarean section. $N$ Engl $J$ Med 1996;335(10):689-95.

13. Berger MB, Doumouchtsis SK, Delancey JO. Are bony pelvis dimensions associated with levator ani defects? A case-control study. Int Urogynecol J 2013;24(8):1377-83.

14. Woon JT, Perumal V, Maigne JY, Stringer MD. CT morphology and morphometry of the normal adult coccyx. Eur Spine J 2013;22(4): 863-70.

15. Keller TM, Rake A, Michel SC, Seifert B, Efe $\mathrm{G}$, Treiber K, et al. Obstetric MR pelvimetry: reference values and evaluation of inter- and intraobserver error and intraindividual variability. Radiology 2003;227(1):37-43.

16. Ridgeway B, Arias BE, Barber MD. The relationship between anthropometric measurements and the bony pelvis in African American and European American women. Int Urogynecol J 2011;22(8):1019-24.

17. Harper LM, Odibo AO, Stamilio DM, Macones GA. Radiographic measures of the mid pelvis to predict cesarean delivery. Am J Obstet Gynecol 2013;208(6):460.e1-6.

18. Hampel F, Hallscheidt $P$, Sohn $C$, Schlehe B, Brocker KA. Pelvimetry in nulliparous and primiparous women using 3 Tesla magnetic resonance imaging. Neurourol Urodyn 2018 Feb 21. Doi: 10.1002/nau.23537. [Epub ahead of print].

19. Franz M, von Bismarck A, Delius M, Ertl-Wagner B, Deppe C, Mahner S, et al. MR pelvimetry: prognosis for successful vaginal delivery in patients with suspected fetopelvic disproportion or breech presentation at term. Arch Gynecol Obstet 2017;295(2):351-9.

20. Hoffmann J, Thomassen K, Stumpp $P$, Grothoff M, Engel C, Kahn T, et al. New MRI criteria for successful vaginal breech delivery in primiparae. PLOS One 2016;11(8): e0161028. 